\title{
Increased expression of the long non-coding RNA ANRIL promotes lung cancer cell metastasis and correlates with poor prognosis
}

\author{
Ling Lin, Zhi-Tao Gu, Wen-Hu Chen and Ke-Jian Cao*
}

\begin{abstract}
Background: Emerging evidences indicate that dysregulated long non-coding RNAs (IncRNAs) are implicated in cancer tumorigenesis and progression. LnCRNA ANRIL has been shown to promote the progression of gastric cancer. However, the role of IncRNA ANRIL in human non-small cell lung cancer (NSCLC) remains unclear.

Methods: Expression of InCRNA ANRIL was analyzed in 87 NSCLC tissues and three lung cancer cell lines by quantitative real-time PCR (qRT-PCR). The correlation of IncRNA ANRIL with clinicopathological features and prognosis was analyzed. Suppression of IncRNA ANRIL using siRNA treatment was performed in order to explore its role in tumor progression.

Results: The expression level of IncRNA ANRIL was higher in NSCLC tissues and lung cancer cells than in adjacent non-tumor tissues and normal human bronchial epithelial cells. Higher expression of InCRNA ANRIL in NSCLC tissues was associated with higher TNM stage and advanced lymph node metastasis. Patients with high IncRNA ANRIL expression had poorer overall survival compared with low IncRNA ANRIL group. Univariate and multivariate analyses suggested that high expression of IncRNA ANRIL was an independent poor prognostic indicator for NSCLC patients. Moreover, knockdown of IncRNA ANRIL expression could inhibit lung cancer cell proliferation, migration and invasion in vitro.
\end{abstract}

Conclusions: Our results suggested that InCRNA ANRIL was a potential biomarker for NSCLC prognosis, and the dysregulation of IncRNA ANRIL may play an important role in NSCLC progression.

Virtual Slides: The virtual slide(s) for this article can be found here: http://www.diagnosticpathology.diagnomx.eu/ vs/1707061287149690.

Keywords: Non-small cell lung cancer, Long non-coding RNAs, ANRIL, Prognosis

\section{Background}

Lung cancer is one of the leading causes of all cancerrelated deaths worldwide, and with an incidence of over 200000 new cases every year [1]. Approximately, 85\% of all lung cancer cases are categorized as non-small cell lung cancer (NSCLC), and more than $50 \%$ of NSCLC patients have advanced local invasion and/or distant metastases [2]. Despite much progress in early detection and treatment, the 5-year survival rate for NSCLC patients at later stages is only $5-20 \%$ [3]. Therefore, it is necessary for us to discover the underlying molecular

\footnotetext{
* Correspondence: kejianc73@163.com

Department of Thoracic Surgery, Shanghai Chest Hospital, Shanghai Jiaotong University, 241 West Huaihai Road, Shanghai 200030, China
}

mechanisms and screen useful biomarkers and novel therapeutic targets of NSCLC.

Traditionally, cancer was regarded as a genetic disease, but current research revealed that cancer development and progression involves epigenetic abnormalities [4]. Genetic continuity has been shown to involve epigenetic regulation such as DNA methylation, histone deacetylation and non-coding RNA (ncRNA) regulation [5]. Long non-coding RNAs (lncRNAs) are more than 200 nucleotides in length with limited or no protein-coding capacity and serve as the primary regulatory ncRNA [6]. Increasing evidences showed that IncRNAs could play an important role in cellular development, differentiation, and many other biological processes [7-9]. 
Polycomb repressive complex 2 (PRC2) contained the core subunits SUZ12, EED and EZH2 and regulated transcription by establishing di- and trimethylation of histone H3 lysine 27 (H3K27me2 and H3K27me3), critical epigenetic silencing marks [10]. PRC2 target genes played key roles in cell cycle regulation, stem cell selfrenewal and cell fate decisions and are frequently targeted for epigenetic modulation in cancer [11]. Recent studies showed that PRC2 could act as an oncogene or tumor suppressor in tumors [12]. IncRNA ANRIL was reported to have a direct role in recruiting PRC2 complexes to specific loci and repress gene expression [13].

ANRIL (antisense non-coding RNA in the INK4 locus), a $3.8 \mathrm{~kb}$ lncRNA expressed in the opposite direction from INK4A-ARF-INK4B gene cluster [14]. Common disease genomewide association studies showed ANRIL gene as a genetic susceptibility locus shared associated by coronary disease, intracranial aneurysm, type 2 diabetes and also cancers [15]. Yap et al. found that lncRNA ANRIL was significantly up-regulated in prostate cancer and involved in repressing of the p15/ CDKN2B-p16/CDKN2Ap14/ARF gene cluster in Cis by directly binding to the PRC [16]. Zhang et al. showed that lncRNA ANRIL was increased in gastric cancer and associated with tumor size and advanced TNM stage. Further experiments revealed that ANRIL knockdown significantly repressed the proliferation both in vitro and in vivo [17]. However, IncRNA ANRIL expression in NSCLC and the underlying mechanism is still unknown.

In this study, the biological functions of IncRNA ANRIL in NSCLC development were explored by examining the expression pattern of IncRNA ANRIL in NSCLC tissues. Moreover, analysis of existent association with both clinicopathological features and prognosis were examined in order to determine whether IncRNA ANRIL could be considered a potential prognostic factor for the prediction of clinical outcomes in NSCLC patients. Finally, we conducted in vitro assay to demonstrate the biological functions of lncRNA ANRIL on NSCLC progression.

\section{Methods}

\section{Patients and specimens}

A total of 87 primary NSCLC patients were collected from the Department of General Thoracic Surgery, Shanghai Chest Hospital between 2004 and 2006. All patients did not receive chemotherapy or radiotherapy prior to surgery. The clinicopathological findings were determined according to the classification of malignant tumors by the World Health Organization and International Union against Cancer Tumor-NodeMetastasis (TNM) staging system $[18,19]$. NSCLC tumor tissues and their matched non-tumor tissues were immediately frozen in liquid nitrogen and stored at $-70^{\circ} \mathrm{C}$ until use. This study was approved by the Research Ethics Committee of Shanghai Chest Hospital. Informed consent was obtained from all of the patients. The clinicopathological features of patients are summarized in Table 1.

\section{Cell culture and transfection}

Three lung cancer cell lines (A549, SPC-A1, NCIH1650) and a normal human bronchial epithelial cell line (16HBE) were purchased from the Institute of Biochemistry and Cell Biology of the Chinese Academy of Sciences (Shanghai, China). Cells were cultured in RPMI 1640 (Gibco) medium supplemented with 10\% fetal bovine serum (FBS), $100 \mathrm{U} / \mathrm{ml}$ penicillin, and $100 \mathrm{mg} / \mathrm{ml}$ streptomycin in humidified air at $37^{\circ} \mathrm{C}$ with $5 \% \mathrm{CO}_{2}$.

Lung cancer cells were transfected with either $50 \mathrm{nM}$ siRNAs targeting ANRIL (si-ANRIL) or scrambled negative controls (si-NC) (GenePharma) using the Lipofectamine 2000 transfection reagent (Invitrogen) according to the instructions provided by the manufacturer. The target sequence for ANRIL siRNAs was 5'-GGUCAUCU CAUUGCUCUAU-3' [13]. After $24 \mathrm{~h}$, knockdown of ANRIL was confirmed via qRT-PCR.

\section{Cell proliferation assay}

The in vitro cell proliferation of lung cancer cells was measured using the MTT method. In brief, cells were seeded into 96-well plates and transfected with $50 \mathrm{nM}$ si-ANRIL or si-NC for $24 \mathrm{~h}$. In the indicated time periods, $0.1 \mathrm{ml}$ of spent medium was replaced with an equal volume of fresh medium containing MTT $0.5 \mathrm{mg} / \mathrm{ml}$. Plates were incubated at $37^{\circ} \mathrm{C}$ for 4 hours, and then the medium was replaced with $0.1 \mathrm{ml}$ of

Table 1 Correlation between IncRNA ANRIL expression and clinicopathological features in NSCLC patients

\begin{tabular}{|c|c|c|c|c|c|}
\hline \multirow[t]{2}{*}{ Parameters } & \multirow[t]{2}{*}{ Group } & \multirow[t]{2}{*}{ Total } & \multicolumn{2}{|c|}{ IncRNA ANRIL } & \multirow[t]{2}{*}{$P$ value } \\
\hline & & & Low & High & \\
\hline \multirow[t]{2}{*}{ Gender } & Male & 51 & 23 & 28 & \multirow[t]{2}{*}{0.952} \\
\hline & Female & 36 & 16 & 20 & \\
\hline \multirow[t]{2}{*}{ Age (years) } & $<60$ & 42 & 18 & 24 & \multirow[t]{2}{*}{0.721} \\
\hline & $\geq 60$ & 45 & 21 & 24 & \\
\hline \multirow[t]{2}{*}{ Tumor size $(\mathrm{cm})$} & $<3 \mathrm{~cm}$ & 39 & 16 & 23 & \multirow[t]{2}{*}{0.520} \\
\hline & $\geq 3 \mathrm{~cm}$ & 48 & 23 & 25 & \\
\hline \multirow[t]{2}{*}{ Histology } & Adenocarcinoma & 38 & 20 & 18 & 0.197 \\
\hline & $\begin{array}{l}\text { Squamous cell } \\
\text { carcinoma }\end{array}$ & 49 & 19 & 30 & \\
\hline \multirow[t]{2}{*}{ TNM stage } & 1 & 26 & 19 & 7 & \multirow[t]{2}{*}{0.001} \\
\hline & $\|-\| \|$ & 61 & 20 & 41 & \\
\hline \multirow{2}{*}{$\begin{array}{l}\text { Lymph node } \\
\text { metastasis }\end{array}$} & Absence & 40 & 32 & 8 & \multirow[t]{2}{*}{0.000} \\
\hline & Presence & 47 & 7 & 40 & \\
\hline
\end{tabular}


DMSO (Sigma) and plates were agitated at room temperature for $10 \mathrm{~min}$. The absorbance was measured at $490 \mathrm{~nm}$ using an enzyme-labeled analyzer.

\section{Cell migration and invasion assays}

Lung cancer cells were transfected with $50 \mathrm{nM}$ si-ANRIL or si-NC. After $24 \mathrm{~h}$, transfected cells were harvested. In migration assay, transfected cells $\left(1 \times 10^{5}\right)$ were plated in the top chamber of Transwell assay inserts (Millipore) with a membrane containing pores with $8 \mathrm{~mm}$ diameters in $200 \mathrm{ml}$ of serum-free RPMI1640. Assays were conducted in triplicate. Inserts were then placed into the bottom chamber wells of a 24-well plate containing RPMI1640 with 10\% FBS as a chemoattractant. After $24 \mathrm{~h}$ of incubation, remaining cells were removed from the top layer of the insert by scrubbing with a sterile cotton swab. Invading cells from the bottom surface were stained with $0.1 \%$ crystal violet prior to being examined, counted and photographed using digital microscopy. Cell numbers were calculated in five random fields for each chamber, and the average value was calculated. In invasion assay, transfected cells $\left(4 \times 10^{5}\right)$ were plated in the top chamber with a Matrigel-coated membrane. Bottom chambers were filled with conditioned medium. After a $48 \mathrm{~h}$ incubation period, the number of migrated cells on the lower side of the membrane was counted as described previously.

\section{Quantitative realtime PCR (qRT-PCR)}

Total RNA was extracted from tissues or cultured cells using TRIzol reagent (Invitrogen). For qRT-PCR, RNA was reverse transcribed to cDNA by using a Reverse Transcription Kit (Takara). Real-time PCR analyses were performed with Power SYBR Green (Takara). Results were normalized to the expression of GAPDH. The PCR primers for ANRIL or GAPDH were as follows: ANRIL sense, 5' - TGCTCTATCCGCCAATCAGG-3' and reverse, 5'-GGGCCTCAGTGGCACATACC-3'; GAPDH sense, 5'-GTCAACGGATTTGGTCTGTATT-3' and reverse, 5'-AGTCTTCTGGGTGGCAGTGAT-3'. qRTPCR and data collection were performed on ABI 7900. The relative expression of ANRIL was calculated and normalized using the $2^{-\Delta \Delta \mathrm{Ct}}$ method relative to GAPDH.

\section{Statistical analysis}

All statistical analyses were performed using SPSS version 18.0 software (IBM). Comparison of continuous data was analyzed using an independent $t$-test between the two groups, whereas categorical data was analyzed by the chi-square test. Overall survival curves were plotted according to the Kaplan-Meier method, with the log-rank test applied for comparison. A Cox proportional hazards regression analysis was used for univariate and multivariate analyses of prognostic values. The data are shown as the mean \pm SD from at least three independent experiments. Values of P less than 0.05 were considered statistically significant.

\section{Results}

LncRNA ANRIL was up-regulated in NSCLC tissues

qRT-PCR assay was performed to detect the expression of IncRNA ANRIL in 87 NSCLC tissues and corresponding non-tumor tissues. As shown in Figure 1A, the relative level of lncRNA ANRIL expression was significantly higher in NSCLC tissues than in adjacent non-tumor tissues $(P<0.05)$. To assess the correlation of lncRNA ANRIL expression with clinicopathologic features, according to the mean value of relative lncRNA ANRIL expression (3.6) in tumor tissues, the 87 NSCLC patients were classified into two groups: relative high-ANRIL group: ANRIL expression ratio $\geq$ mean; relative lowANRIL group: ANRIL expression ratio < mean (Figure 1B). As shown in Table 1, the expression of lncRNA ANRIL was significantly correlated with TNM stage and lymph node metastasis $(\mathrm{P}<0.05)$. However, there were no significant correlations between lncRNA ANRIL expression and other clinicopathologic features including patient's gender, age, tumor size and histology $(\mathrm{P}>0.05)$. Taken together, these observations suggested that increased IncRNA ANRIL expression was associated with the progression and development of NSCLC.

\section{Over-expression of IncRNA ANRIL was associated with poor prognosis of NSCLC}

Kaplan-Meier analysis and log-rank test were used to evaluate the effects of IncRNA ANRIL expression and the clinicopathological features on overall survival of NSCLC patients. As shown in Figure 1C, the overall survival of patients with high lncRNA ANRIL expression was significantly poor than that of those with low lncRNA ANRIL expression $(\mathrm{P}<0.05)$. Univariate analysis showed that TNM stage, lymph node metastasis and lncRNA ANRIL expression were significantly correlated with poor overall survival of NSCLC patients $(\mathrm{P}<0.05$; Table 2). Multivariate analysis suggested that relative lncRNA ANRIL expression level, TNM stage and lymph node metastasis were independent prognostic indicators for the overall survival of NSCLC patients (Table 2). These results revealed that IncRNA ANRIL expression could develop as a powerful independent factor for predicting the prognosis of NSCLC patients.

\section{IncRNA ANRIL expression in lung cancer cells and lung cancer cell transfection}

To investigate the roles of lncRNA ANRIL in NSCLC, we performed qRT-PCR to evaluate the levels of ANRIL in three NSCLC cell lines and one normal human bronchial epithelial cell line (16HBE). The expression of 


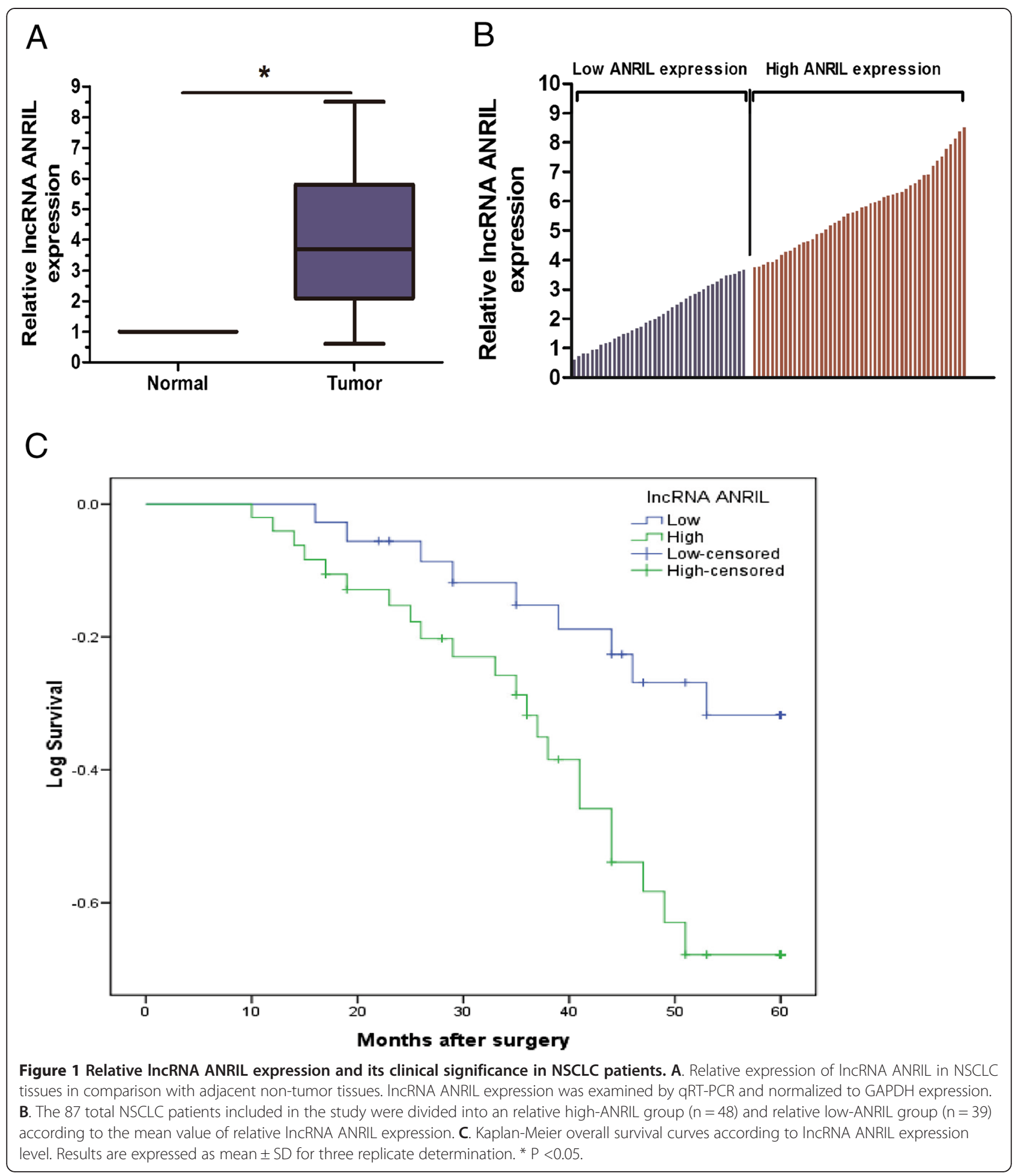

ANRIL was higher in all three cancer cell lines compared with the levels observed in 16HBE cells, with the highest in SPC-A1 cells (Figure 2A). Thus SPC-A1 cells were selected and transfected with si-ANRIL or si-NC. Our results showed that lncRNA ANRIL expression was effectively knocked down in SPC-A1 cells (Figure 2B).
Knockdown IncRNA ANRIL suppressed lung cancer cell growth and metastasis

We investigated the impact of lncRNA ANRIL on the growth of lung cancer cells, MTT assay showed that the proliferation rate of of SPC-A1 cells transfected with siANRIL was significantly decreased compared with the 
Table 2 Univariate and multivariate analysis of prognostic parameters in NSCLC patients by Cox regression analysis

\begin{tabular}{|c|c|c|c|c|c|c|}
\hline \multirow[t]{2}{*}{ Variable } & \multicolumn{3}{|c|}{ Univariate analysis } & \multicolumn{3}{|c|}{ Multivariate analysis } \\
\hline & Risk ratio & $95 \% \mathrm{Cl}$ & P-value & Risk ratio & $95 \% \mathrm{Cl}$ & P-value \\
\hline Gender & 1.328 & $0.653-2.344$ & 0.552 & & & \\
\hline \multicolumn{7}{|l|}{ Male vs female } \\
\hline Age (years) & 1.817 & $0.726-3.408$ & 0.472 & & & \\
\hline \multicolumn{7}{|l|}{$\geq 60$ vs $<60$} \\
\hline Tumor size & 1.533 & $0.874-1.912$ & 0.764 & & & \\
\hline \multicolumn{7}{|l|}{$\geq 3 \mathrm{~cm}$ vs $<3 \mathrm{~cm}$} \\
\hline Histologic grade & 0.892 & $0.531-1.275$ & 0.318 & & & \\
\hline \multicolumn{7}{|c|}{ Squamous cell carcinoma vs adenocarcinoma } \\
\hline TNM stage & 2.936 & $1.526-5.712$ & 0.007 & 2.517 & $1.368-5.215$ & 0.011 \\
\hline \multicolumn{7}{|l|}{ II-III vs I } \\
\hline Lymph node metastasis & 3.371 & $1.484-6.933$ & $<0.001$ & 2.868 & $1.392-6.173$ & 0.006 \\
\hline \multicolumn{7}{|l|}{ Presence vs absence } \\
\hline IncRNA ANRIL & 2.793 & $1.425-5.791$ & 0.002 & 2.538 & $1.374-5.452$ & $<0.001$ \\
\hline
\end{tabular}

High vs low

si-NC group $(\mathrm{P}<0.05$, Figure $3 \mathrm{~A})$. Next, Transwell migration and invasion assays were used to examine the effect of lncRNA ANRIL on lung cancer cell metastasis. Transwell migration assay showed that the migration ability of SPC-A1 cells transfected with si-ANRIL was significantly decreased compared with the si-NC group $(\mathrm{P}<0.05$, Figure $3 \mathrm{~B})$. Transwell invasion assay revealed that the invasion capacity of SPC-A1 cells transfected with si-ANRIL was notably down-regulated compared to si-NC group $(\mathrm{P}<0.05$, Figure $3 \mathrm{C})$. These results suggested that lncRNA ANRIL could promote the growth and metastasis of lung cancer cells.

\section{Discussion}

The sequencing of the human genome revealed that the coding portion of the genome represents less than $2 \%$ of the genome. The remaining $98 \%$ of transcription products of the genome consists of non-coding RNA sequences, including microRNAs and lncRNAs [20]. Recently, numerous pieces of evidence showed that dysregulation in lncRNAs are proved to contribute in tumor development in many cancer types and can be used to develop as biomarkers and therapy target [21]. For example, Zhang et al. demonstrated that lncRNA SPRY4IT1 (SPRY4 intronic transcript 1) was increased in clear cell renal cell carcinoma (ccRCC) tissues and ccRCC patients with higher SPRY4-IT1 expression had an advanced clinical stage and poorer prognosis [22]. Wang et al. showed that lncRNA PlncRNA-1 was significantly higher in human esophageal squamous cell carcinoma and correlated with advanced clinical stage and lymph node metastasis. Knockdown of PlncRNA-1 reduced cell proliferation and increased the apoptosis in vitro [23]. Sun et al. found that GAS5 (Growth arrest-specific 5) expression was markedly down-regulated in gastric cancer and associated poorer disease-free survival and
A

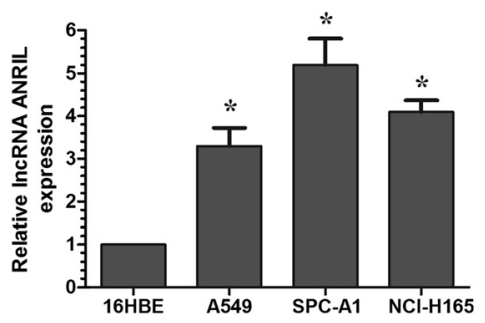

B

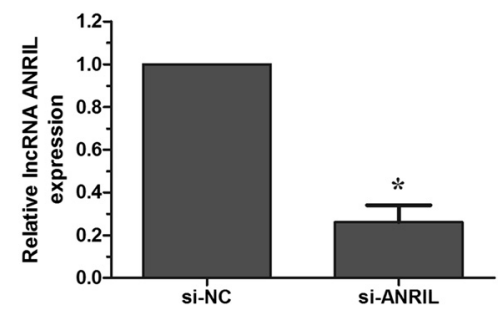

Figure 2 Relative IncRNA ANRIL expression level in lung cancer cells. A. Analysis of InCRNA ANRIL expression levels in NSCLC cell lines (A549, SPC-A1, NCI-H1650) compared with the normal bronchial epithelial cell line (16HBE) by qRT-PCR. B. Analysis of IncRNA ANRIL expression following treatment of SPC-A1 cells with si-ANRIL or si-NC by qRT-PCR. Results are expressed as mean \pm SD for three replicate determination. * $\mathrm{P}<0.05$. 


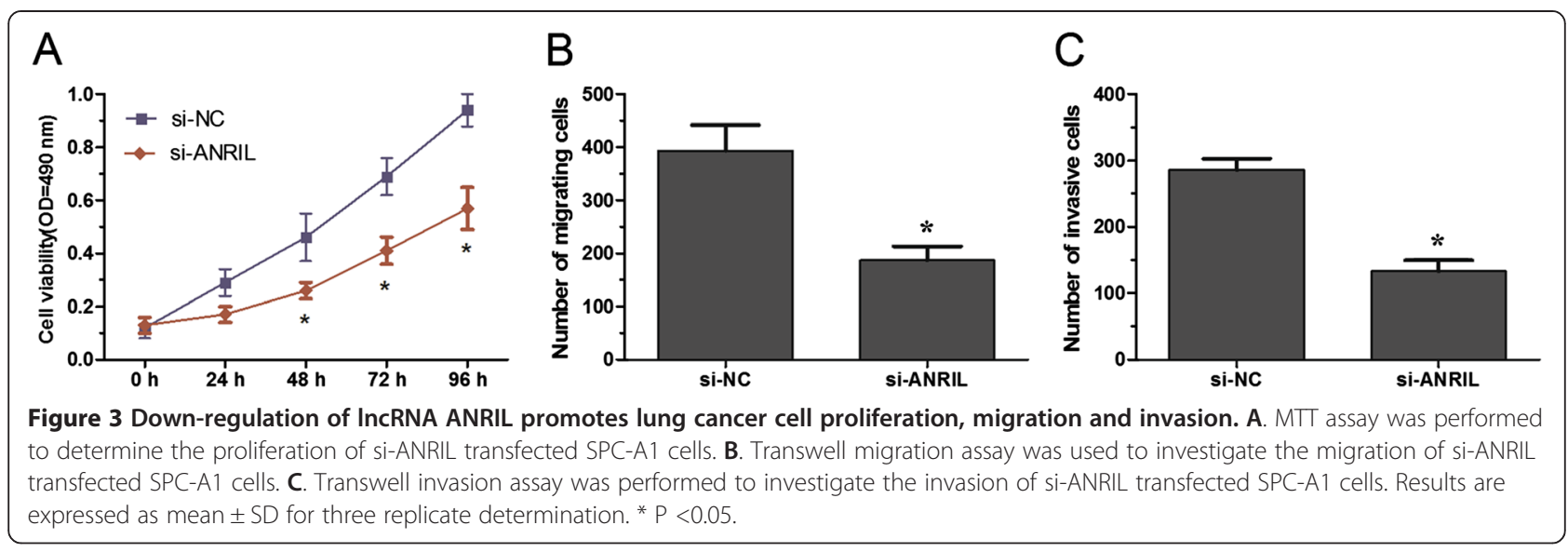

overall survival of gastric cancer patients. Moreover, ectopic expression of GAS5 was demonstrated to decrease gastric cancer cell proliferation and induce apoptosis in vitro and in vivo [24]. However, the expression profile and potential function of lncRNA ANRIL in NSCLC is still unknown.

In the study, we explored the clinical significance of IncRNA ANRIL in NSCLC patients for the first time. By using qRT-PCR, we found that lncRNA ANRIL was increased in NSCLC tissues and lung cancer cell lines to a greater extent than in adjacent non-tumor tissues and normal human bronchial epithelial cell line. We also revealed that the relative expression level of lncRNA ANRIL was associated with TNM stage and lymph node metastasis of NSCLC patients. These findings suggested that a higher level of lncRNA ANRIL expression may be involved in NSCLC pathogenesis and progression.

Furthermore, we analyzed a correlation between IncRNA ANRIL expression level and prognosis of NSCLC. Our results showed patients with high lncRNA ANRIL expression had a shorter overall survival rate than those with low lncRNA ANRIL group. These findings were further supported by the univariate and multivariate analyses of Cox proportional hazards regression model, indicating that the expression of lncRNA ANRIL could be an independent factor for predicting the prognosis of NSCLC patients. Therefore, our data demonstrated that increased expression of IncRNA ANRIL was associated with an high risk of death from NSCLC. Then, we analyzed the effect of IncRNA ANRIL expression on the growth and metastasis of lung cancer cells. We found that down-regulated expression of lncRNA ANRIL significantly decreased proliferation, migration and invasion capability of lung cancer cells in vitro. These data further support the importance of ANRIL in cellular biology and oncogenesis of lung cancer cells and indicate that ANRIL is involved in the development and progression of NSCLC.

\section{Conclusion}

In summary, our study demonstrated that the expression level of lncRNA ANRIL was increased in NSCLC tissues compared to that in the adjacent non-tumor tissues. Elevated IncRNA ANRIL expression has been associated with poor prognosis of overall survival, likely due to the ability of lncRNA ANRIL to promote cell growth and metastasis in lung cancer cells. These results indicated that IncRNA ANRIL played a critical role in the progression of NSCLC. The development of ANRIL-based therapeutic strategies for the downregulation of such oncogenic lncRNAs may provide a novel and promising alternative therapeutic approach for future cancer treatment.

\section{Abbreviations \\ IncRNAs: Long non-coding RNAs; ncRNA: Non-coding RNA; NSCLC: Non- small cell lung cancer; ccRCC: Clear cell renal cell carcinoma; TNM: Tumor- node-metastasis; DMSO: Dimethyl sulfoxide; FBS: Fetal bovine serum; ANRIL: Antisense non-coding RNA in the INK4 locus; SPRY4-IT1: SPRY4 intronic transcript 1; GAS5: Growth arrest-specific 5; siRNA: Small interfering RNA; Si-ANRIL: siRNAs targeting ANRIL; si-NC: Scrambled negative control; qRT-PCR: Quantitative real-time PCR; GAPDH: Glyceraldehyde-3-phosphate dehydrogenase; MT: 3-(4,5)-dimethylthiahiazo (-z-y1)-3,5-di- phenytetrazoliumromide; PRC2: Polycomb repressive complex 2.}

\section{Competing interests}

The authors declare that they have no competing interests.

\section{Authors' contributions}

Conceived and designed the experiments: LL KJC. Performed the experiments: LL ZTG WHC. Analyzed the data: ZTG WHC. Contributed reagents/materials/analysis tools: LL WHC. Wrote the paper: LL KJC. All authors read and approved the final manuscript.

Received: 13 November 2014 Accepted: 11 March 2015

Published online: 27 March 2015

\section{References}

1. Jemal A, Bray F, Center MM, Ferlay J, Ward E, Forman D. Global cancer statistics. CA Cancer J Clin. 2011;61:69-90.

2. Goldstraw P, Ball D, Jett JR, Le Chevalier T, Lim E, Nicholson AG, et al. Non-small-cell lung cancer. Lancet. 2011;378:1727-40.

3. Molina JR, Yang P, Cassivi SD, Schild SE, Adjei AA. Non-small cell lung cancer: epidemiology, risk factors, treatment, and survivorship. Mayo Clin Proc. 2008;83:584-94. 
4. Jones PA, Baylin SB. The epigenomics of cancer. Cell. 2007;128:683-92.

5. Feinberg AP, Ohlsson R, Henikoff $S$. The epigenetic progenitor origin of human cancer. Nat Rev Genet. 2006;7:21-33.

6. Mercer TR, Dinger ME, Mattick JS. Long non-coding RNAs: insights into functions. Nat Rev Genet. 2009;10:155-9.

7. Stefani G, Slack FJ. Small non-coding RNAs in animal development. Nat Rev Mol Cell Biol. 2008;9:219-30.

8. Hu W, Alvarez-Dominguez JR, Lodish HF. Regulation of mammalian cell differentiation by long non-coding RNAs. EMBO Rep. 2012;13:971-83.

9. Gibb EA, Brown CJ, Lam WL. The functional role of long non-coding RNA in human carcinomas. Mol Cancer. 2011;10:38.

10. Margueron R, Reinberg D. The Polycomb complex PRC2 and its mark in life. Nature. 2011:469:343-9.

11. Sparmann A, van Lohuizen M. Polycomb silencers control cell fate, development and cancer. Nat Rev Cancer. 2006;6:846-56.

12. Esteller M. Epigenetics provides a new generation of oncogenes and tumour-suppressor genes. Br J Cancer. 2006:94:179-83.

13. Kotake Y, Nakagawa T, Kitagawa K, Suzuki S, Liu N, Kitagawa M, et al. Long non-coding RNA ANRIL is required for the PRC2 recruitment to and silencing of p15(INK4B) tumor suppressor gene. Oncogene. 2011;30:1956-62.

14. Wan G, Mathur R, Hu X, Liu Y, Zhang X, Peng G, et al. Long non-coding RNA ANRIL (CDKN2B-AS) is induced by the ATM-E2F1 signaling pathway. Cell Signal. 2013;25:1086-95.

15. Pasmant E, Sabbagh A, Vidaud M, Bieche I. ANRIL, a long, noncoding RNA, is an unexpected major hotspot in GWAS. FASEB J. 2011;25:444-8.

16. Yap KL, Li S, Munoz-Cabello AM, Raguz S, Zeng L, Mujtaba S, et al. Molecular interplay of the noncoding RNA ANRIL and methylated histone $\mathrm{H} 3$ lysine 27 by polycomb CBX7 in transcriptional silencing of INK4a. Mol Cell. 2010;38:662-74.

17. Zhang EB, Kong R, Yin DD, You LH, Sun M, Han L, et al. Long noncoding RNA ANRIL indicates a poor prognosis of gastric cancer and promotes tumor growth by epigenetically silencing of miR-99a/miR-449a. Oncotarget. 2014;5:2276-92.

18. Kleihues P, Sobin LH. World Health Organization classification of tumors. Cancer. 2000;88:288.

19. Sobin LH, Fleming ID. TNM Classification of Malignant Tumors, fifth edition (1997). Union Internationale Contre le Cancer and the American Joint Committee on Cancer. Cancer. 1997;80:1803-4.

20. International Human Genome Sequencing Consortium. Finishing the euchromatic sequence of the human genome. Nature. 2004;431:931-45.

21. Prensner JR, Chinnaiyan AM. The emergence of IncRNAs in cancer biology. Cancer Discov. 2011;1:391-407.

22. Zhang HM, Yang FQ, Yan Y, Che JP, Zheng JH. High expression of long non-coding RNA SPRY4-IT1 predicts poor prognosis of clear cell renal cell carcinoma. Int J Clin Exp Pathol. 2014;7:5801-9.

23. Wang CM, Wu QQ, Li SQ, Chen FJ, Tuo L, Xie HW, et al. Upregulation of the long non-coding RNA PIncRNA-1 promotes esophageal squamous carcinoma cell proliferation and correlates with advanced clinical stage. Dig Dis Sci. 2014;59:591-7.

24. Sun M, Jin FY, Xia R, Kong R, Li JH, Xu TP, et al. Decreased expression of long noncoding RNA GAS5 indicates a poor prognosis and promotes cell proliferation in gastric cancer. BMC Cancer. 2014;14:319

\section{Submit your next manuscript to BioMed Central and take full advantage of:}

- Convenient online submission

- Thorough peer review

- No space constraints or color figure charges

- Immediate publication on acceptance

- Inclusion in PubMed, CAS, Scopus and Google Scholar

- Research which is freely available for redistribution 